\title{
Urgences
}

\section{Deux cantouques retrouvés de Gérald Godin}

\section{André Gervais et}

Numéro 33, octobre 1991

Poésies parallèles : France - Québec

URI : https://id.erudit.org/iderudit/025675ar

DOI : https://doi.org/10.7202/025675ar

Aller au sommaire du numéro

Éditeur(s)

Urgences

ISSN

0226-9554 (imprimé)

1927-3924 (numérique)

Découvrir la revue

Citer ce document

Gervais, A. \& (1991). Deux cantouques retrouvés de Gérald Godin. Urgences, (33), 124-128. https://doi.org/10.7202/025675ar d'utilisation que vous pouvez consulter en ligne.

https://apropos.erudit.org/fr/usagers/politique-dutilisation/ 


\section{Deux cantouques retrouvés}

Gérald Godin

Ayant terminé, à toutes fins utiles, en septembre 1990, la recherche en vue de l'annotation de l'entretien qui accompagne le recueil de Gérald Godin paru récemment*, c'est seulement un an plus tard que, replongeant dans les classeurs et dossiers de l'auteur, j'ai eu l'occasion de mettre la main, à ma grande surprise, sur.... deux autres cantouques.

De la même façon que les deux * cantouques * inédits que propose ce choix de poèmes (p. 77-80) viennent du dactylogramme du recueil intitulé Les cantouques (1967), le premier "cantouque * ici publié vient du dactylogramme du recueil intitulé Nouveaux poèmes (1963).

Quant au second * cantouque*, l'auteur confirme qu'il a été écrit sur le coup de manifestations qui ont eu lieu à Montréal en 1965, ou peu après**.

Il semblerait que nous ayons, maintenant, tous les "cantouques».

André Gervais septembre 1991

* Gérald Godin, Cantouques \& Cio, choix de poèmes suivi d'un entretien, édition préparée par André Gervais, coll. * Typo ", Montréal, l'Hexegone, [août] 1991.

- Voir Louis Fournier, F.L.Q. Histoire d'un mouvement clandestin, Montréal, Québec-Amérique, 1982, p. 106-109. 


\section{Cantouque de ma jeunesse}

c'était dans une taverne rue de l'Alverne

je me souviens je me souviens

même l'image est changée

que de moi je vous ai donnée toutes ces années

ce n'est pas encore ce ne sera jamais des migrations des voyages l'arrêt on n'a pas été jeune en vain si chaque jour que la nuit tombe que l'hiver vienne que l'été s'en aille si chaque jour de coeur attentif d'oreille et d'œil vif nous a trouvé

dans l'espace il s'est levé un homme c'est une maison en ruines quelque part entre Quinag et Loch Assynt en Écosse un homme s'est levé rue de l'Alverne dans une taverne à la fois plein de souvenirs un cimetière intérieur mais aussi les fenêtres ouvertes aux vents et à la mer entre Quinag et l'univers entre le golfe et les montagnes c'était je me souviens je me souviendrai le jour de la Saint-Maur en janvier les années sont des écailles dit-il quand elles sont toutes après tant d'automnes et tant d'hivers tant d'étés de primevères quand toutes elles sont tombées que la vie repose à nos pieds le soleil bat contre les parois du ciel et n'est qu'une des cloches de la sagesse

tant avons de souvenirs tant de fois nous bat le cœur 
126

en une seule journée tant de fois les heures

ne portent à la mémoire qu'une histoire toujours la même vieille inchangée

c'était à la Saint-Maur

il s'est levé un homme

un fleuve n'est qu'un mot sans cesse écrit dit-il

le livre est infini de la présence à la vie

c'était rue de l'Alverne

les mélèzes de Moidart

et les falaises dit-il

l'Amazonie le Ligugé

l'histoire de l'art

et les brancards

de la pensée

Dieu dut être comme lui avant de mourir

à la fois l'orbe et la main qui le tient

c'était une taverne ravaudeuse

les âmes y venaient (je me souviens de ma jeunesse)

où toute la bière du monde était réfugiée

la dernière peut-être où l'on reprisa

les cours au catalpa de Caroline

aux fleurs en corymbe à l'extrémité des rameaux

il s'est levé un homme qui n'était pas beau

mais un homme tout de même et sans honte

je me souviens je me souviens

ni la semure d'étoiles ni la lune

ne me sont à jalousie ni vos vies dit-il

je trace les fleuves à main levée

la mer la mer est mon encrier

c'était une taverne

la seule sans doute entre le golfe et les montagnes la seule où Dieu vint un soir et s'enquit au waiter d'une langue de veau et d'une pilseneur 


\section{Cantouque de la veillée québécoise (air bête et connu)}

la seagull ayant grincé tout l'été tape la ribidoune et pis tapoche encore se trouva fort détenue quand la police fut venue

c'est pas moi c'est eux autres tape la police et pis tapoche encore qu'ont cassé toutes les dents de Reggie ti guerlot gros guerlot guerleton glin-glon

par un dimanche au soir m'en allant promener par la police me suis fait arrêter j'ai vu des hommes des femmes des filles j'ai vu des hommes des femmes rossés

m'en revenant du parc Lafontaine trois détectives j'ai rencontré j'ai point choisi y m'ont saisi tape la police et pis tapoche encore

derrière chez nous j'suis pas chez nous et même chez nous je suis chez eux visa patrie tua pays

Ottawa s'en va boitant avec mon grand fusil d'argent

tape la police et pis tapoche encore toutes mes belles plumes s'en vont au vent libera nos morpionibou avant qu'on soit tout à fait fous

du grand mât d'une corvette mon beau pays un soir tomba tapent les Anglais et pis tapochent encore j’ai vu Richard Florent et Reggie j'ai vu Richard et Florent maganés guerletons tordus 
128

le Prin Syphilippe s'en va chassant avec sa belle maturité

le grand troutcul s'en va chasser tape sur la bizoune tua coq d'inde le petit mousse un soir tomba 